\begin{tabular}{|c|l|}
\hline Title & A pplicability of heat transfer equations to hydrogen combustion \\
\hline Author(s) & Shudo, Toshio; Suzuki, Hiroyuki \\
\hline Citation & $\begin{array}{l}\text { JSAE Review, 23(3), 303 308 } \\
\text { https://doi.org/10.1016/S0389-4304(02)00193-5 }\end{array}$ \\
\hline Issue Date & $2002-07$ \\
\hline Doc URL & http://hdl.handle.net/2115/32325 \\
\hline Type & article (author version) \\
\hline File Information & JSAE Review 23-3.pdf \\
\hline
\end{tabular}

Instructions for use 


\title{
Applicability of heat transfer equations to hydrogen combustion
}

\section{Toshio SHUDO}

Applied Energy System Group, Division of Energy and Environmental Systems, Hokkaido University

N13 W8, Kita-Ward, Sapporo, Hokkaido, 060-8628, JAPAN

Email: shudo@eng.hokudai.ac.jp

Tel/Fax: +81-11-706-6402

Hiroyuki SUZUKI

Graduate School, Musashi Institute of Technology, Tokyo

\begin{abstract}
Previous research by the authors showed that hydrogen combustion exhibits a higher cooling loss to the combustion chamber wall of an internal combustion engine compared to hydrocarbon combustion because of its higher burning velocity and shorter quenching distance. The high cooling loss means that reduction of the cooling loss is essential to establish a high thermal efficiency in hydrogen combustion engines. This research analyzed the applicability of equations to describe the heat transfer from burning gases to hydrogen combustion. The result shows that equations calculate a lower cooling loss than experimental values, and the use of correction coefficients does not accurately define the actual cooling rate. It is therefore concluded that the derivation of a new heat transfer equation for hydrogen combustion is necessary to improve the thermal efficiency of hydrogen fuelled engines.
\end{abstract}

\section{Introduction}

Hydrogen is an ideal alternative to fossil fuels because of its clean emissions and renewability. It is also suitable for use in internal combustion engines. However, hydrogen has unique combustion characteristics compared with hydrocarbons such as gasoline, diesel fuel and natural gas.

The authors previously analyzed the thermal efficiency characteristics of hydrogen fuelled SI engine and showed that the cooling loss exerts a strong influence on the thermal efficiency of the system [1]. Hydrogen combustion exhibits a high cooling loss from the burning gas to the combustion chamber wall compared to hydrocarbon combustion because of its higher burning velocity and shorter quenching distance. The authors also quantitatively analyzed the cooling loss fraction from the pressure diagram and exhaust gas composition, and showed that hydrogen combustion has a high degree of constant volume cooling [2,3], which was calculated using a newly proposed method to estimate the real rate of heat release using Wiebe's function.

The cooling loss to the combustion chamber wall is the dominating factor in the thermal efficiency of hydrogen combustion engines, and therefore it is essential to reduce the cooling loss in order to maximize the thermal efficiency. The rate of heat release provides useful information for the analysis of thermal efficiency, and is a widely used index. Equations describing the mean heat transfer coefficient on the total area of a combustion chamber wall have already been reported [4-8]. These equations are used for the estimation of the real rate of heat release and the calculation of the total cooling loss to the wall. However, they were derived empirically from observations of engines fuelled with gasoline or diesel fuel. Therefore, the applicability of the equations to hydrogen combustion must be verified before using them for the analysis of hydrogen combustion engines. Hence, the aim of this research is to analyze the suitability of the heat transfer equations to describe the cooling characteristics of a hydrogen fuelled SI engine.

\section{Nomenclature}

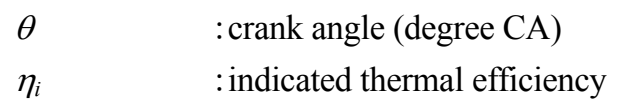




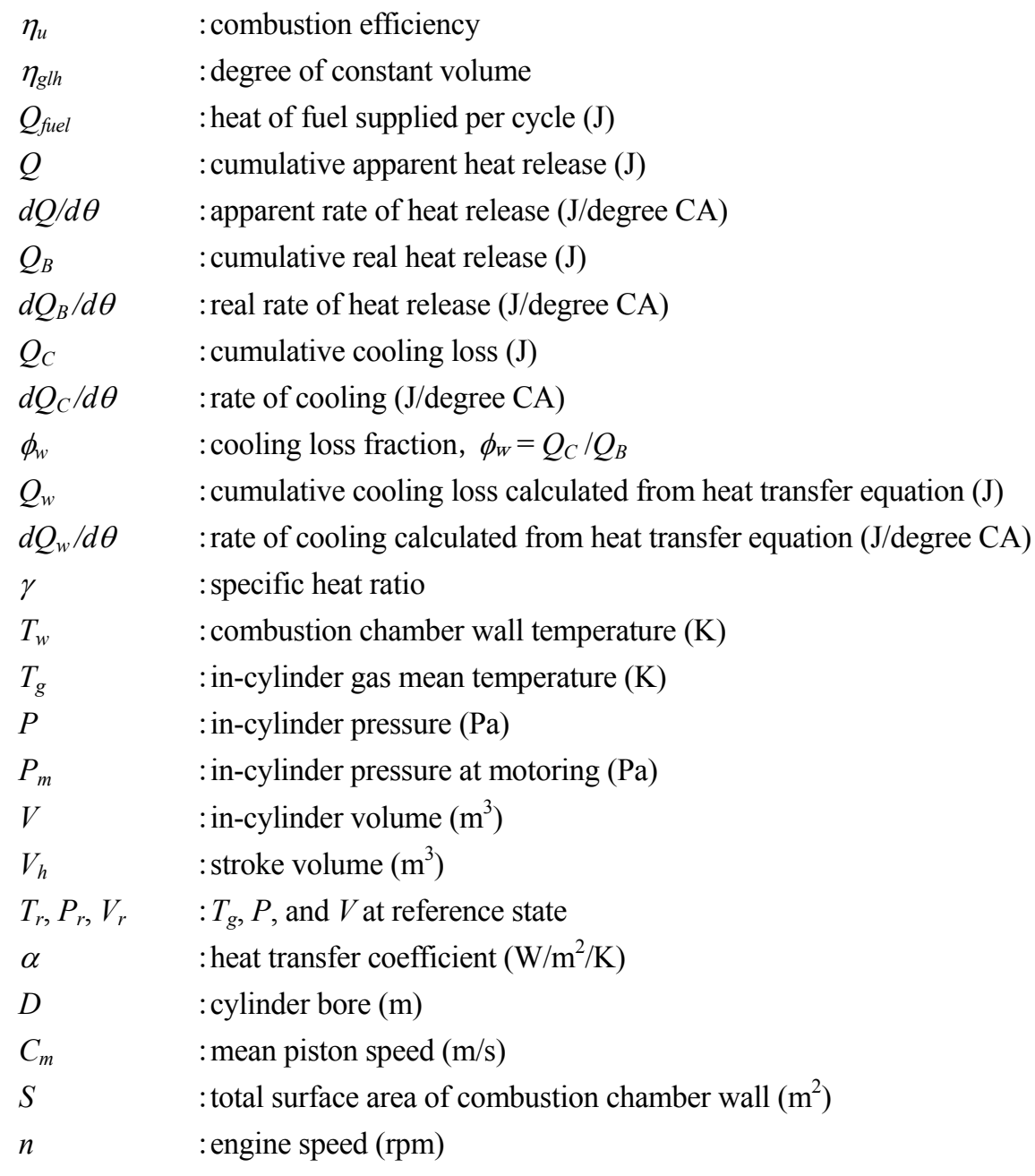

\section{Experimental apparatus and procedure}

Experiments were performed using a 4-cylinder 4-stroke SI gas engine that had been modified from a gasoline engine, as shown in Fig.1. The engine had a bore of $85 \mathrm{~mm}$, a stroke of $88 \mathrm{~mm}$, and a compression ratio of 8.5 . Fuel gas was continuously supplied into the intake manifold for premixed combustion. The in-cylinder pressure was measured with a piezoelectric type pressure transducer (AVL GM12D) installed in the cylinder head. Data from 50 cycles were averaged for each experimental condition and used to calculate the rate of heat release and other factors. The combustion chamber surface temperature was measured with a thin-film type thermocouple installed in the cylinder head.

\section{Analysis}

The apparent rate of heat release $d Q / d \theta$ calculated from the in-cylinder pressure analysis is influenced by the cooling loss due to heat transfer from the burning gas to the combustion chamber wall. It is described using the real rate of heat release $d Q_{B} / d \theta$ and the rate of cooling $d Q_{C} / d \theta$ by the following equation:

$$
d Q / d \theta=d Q_{B} / d \theta-d Q_{C} / d \theta
$$

The relationship is rewritten for one cycle using the cumulative real heat release $Q_{B}$ and the cumulative cooling loss $Q_{C}$ as follows:

$$
Q=Q_{B}-Q_{C}=\eta_{u} Q_{\text {fuel }}-Q_{C}
$$

Heat transfer equations to predict the cumulative cooling loss or the rate of cooling in internal combustion engines have already been reported [4-8]. This research analyzed the applicability of the following five equations for the calculation of the cooling loss characteristics in hydrogen combustion engines:

(1) Woschni's equation

$$
\alpha=0.013 D^{-0.2} P^{0.8} T_{g}^{0.53} w^{0.8}
$$


$w=2.28 C_{m}+0.00324\left(P-P_{m}\right) V_{h} T_{r} /\left(P_{r} V_{r}\right)$

(2) Eichelberg's equation

$\alpha=7.8 \times 10^{-4} P^{0.5} T_{g}^{0.5} C_{m}{ }^{1 / 3}$

(3) Briling's equation

$\alpha=5.41 \times 10^{-4} P^{2 / 3} T_{g}^{1 / 3}\left(3.5+0.185 C_{m}\right)$

(4) Nusselt's equation

$$
\alpha=5.41 \times 10^{-4} P^{2 / 3} T_{g}^{1 / 3}\left(1+1.24 C_{m}\right)
$$

(5) Van Tyen's equation

$$
\alpha=5.46 \times 10^{-4} P^{2 / 3} T_{g}^{1 / 3}\left(3.19+0.885 C_{m}\right)
$$

These empirical equations were based on observations using the turbulent heat transfer equation for tubes.

The rate of cooling calculated from heat transfer equation $d Q_{w} / d \theta$ was calculated in this research using the heat transfer coefficient $\alpha$ from the above equations as follows.

$$
d Q_{w} / d \theta=S \alpha\left(T_{g}-T_{w}\right) / 6 n
$$

The real rate of heat release obtained from $d Q_{w} d \theta$ and $d Q / d \theta$ was analyzed. The apparent rate of heat release was calculated using the following equation.

$$
d Q / d \theta=(V d P / d \theta+\gamma P d V / d \theta) /(\gamma-1)-P V /(\gamma-1)^{2} d \gamma / d \theta
$$

Here, the specific heat ratio $\gamma$ was calculated from the composition and mean temperature of the in-cylinder gas, and treated as a variable. Although $d \gamma / d \theta$ is relatively small in hydrocarbon combustion and is sometimes neglected, hydrogen combustion exhibits a large $d \gamma / d \theta$ due to the rapid change in both the composition and temperature of the in-cylinder gas. The contribution of the third term in the right side of Equation (10) to the apparent rate of heat release is up to $30 \%$ in stoichiometric combustion of hydrogen [9].

\section{Results and Discussion}

\subsection{Applicability of heat transfer equation}

Figure 2 shows a comparison of hydrogen and methane in stoichiometric combustion under various spark ignition timing conditions. The heat release of hydrogen combustion is completed in a shorter period of time than that of methane combustion because of the higher burning velocity. A negative apparent heat release after the end of combustion is significant in hydrogen combustion. Changes in the temperature of the combustion chamber wall during combustion period are also significant. These results clearly suggest a higher cooling loss in hydrogen combustion. Figure 3 shows factors influencing thermal efficiency such as the degree of constant volume and the cooling loss fraction derived from analyses of the in-cylinder pressure data in Fig.2. Here, the cooling loss fraction $\phi_{w}$ was calculated using the following equation [2-3]:

$$
\begin{aligned}
\phi_{w} & =Q_{C} / Q_{B}, Q_{C}=Q_{B}-Q \\
& =\left(Q_{B}-Q\right) / Q_{B}, Q_{B}=\eta_{u} Q_{\text {fuel }} \\
& =1-Q /\left(\eta_{u} Q_{\text {fuel }}\right)
\end{aligned}
$$

Hydrogen combustion achieves a high degree of constant volume even under retarded spark ignition timing conditions because of the short combustion period. However, the indicated thermal efficiency of hydrogen combustion is lower than that of methane combustion because of a significantly higher cooling loss fraction in hydrogen combustion. Therefore, reduction of the cooling loss is essential for the optimization of the thermal efficiency in hydrogen combustion..

Figure 4 shows the cooling loss characteristics calculated using the heat transfer equations from the results in Fig.2 at the optimum ignition timing MBT. The Woschni, Eichelberg, Briling, Nusselt, and Van Tyen equations were used in the calculations. If the cooling loss is correctly calculated by the equations, $d Q / d \theta+d Q_{w} / d \theta$ and $Q^{+} Q_{w}$ in the vertical axis correspond to real rate of heat release $d Q_{B} / d \theta$ and cumulative real heat release $Q_{B}$ respectively. The results of cumulative real heat release of methane combustion show smooth curves reaching a constant value for all the five equations. Conversely, the results of hydrogen combustion are clearly inadequate using any of the five equations. Therefore, they should not used for the analysis of the cooling loss of hydrogen fueled combustion engines. 


\section{2 . Correction Constant for Woschni's equation}

The total cooling loss in a cycle according to Woschni's equation is sometimes different to the cooling loss by experimentation, so correction constants are often used. Figure 5 shows the heat transfer coefficient calculated multiplied by a correction constant $\mathrm{C}$. This constant was determined so as to satisfy the following relationship:

$$
Q+\mathrm{C}_{w}=\eta_{u} Q_{\text {fuel }}
$$

Here, the cumulative apparent heat release and cumulative cooling loss by the equation were integrated until 135degree CA ATDC, which is the exhaust valve opening timing of the tested engine. The combustion efficiency $\eta_{u}$ was obtained from the exhaust gas composition. The figure was normalized using $\left(Q+\mathrm{C} Q_{w}\right) /\left(\eta_{u} Q_{f u e}\right)$. The value of $\left(Q+\mathrm{C} Q_{w}\right) /\left(\eta_{u} Q_{\text {fuel }}\right)$ smoothly tended to 1.0 in methane combustion for any ignition timing. However, some values of hydrogen combustion exceeded 1.0, indicating that the calculated values of $Q+\mathrm{C} Q_{w}$ fails to describe real heat release $\eta_{u} Q_{\text {fuel }}$ in hydrogen combustion.

Figure 6 shows the results of a similar analysis for different excess air ratios in both hydrogen and methane combustion. The value of $\left(Q+\mathrm{C} Q_{w}\right) /\left(\eta_{u} Q_{\text {fuel }}\right)$ in methane combustion smoothly tended to 1.0 for every excess air ratio. However, although sufficiently lean hydrogen combustion with an excess air ratio of 3.0 and a slower burning velocity also approximated this tendency, the trend is not observed with decreasing excess air ratio towards stoichiometric conditions.

Figures 7 and 8 show the constants employed to correct the calculated results by Woschni's equation in Figs.5 and 6. The values of the correction constants for both fuels tended to increase with spark advance, and significantly increased with a decrease in excess air ratio, particularly when the conditions approximated stoichiometric combustion. The correction constant for hydrogen combustion was larger than that for methane combustion and was approximately 4.0 under stoichiometric combustion of hydrogen. This means that cooling loss in hydrogen combustion according to Woschni's equation is smaller than the actual value by $75 \%$.

The results suggest that the application of the heat transfer equations derived for hydrocarbon combustion to hydrogen combustion with significantly different properties is not appropriate. A distinct heat transfer equation for hydrogen combustion is necessary for the analysis of cooling loss to improve the thermal efficiency. A reason for the high cooling loss in hydrogen combustion is the large heat transfer by intense convection between burning gas and the wall due to the high flame propagation velocity of hydrogen $[1,10]$. From the point of view, it seems to be necessary to take the increase in heat transfer coefficient by in-cylinder gas motion due to combustion into consideration for the successful application of a heat transfer equation to hydrogen combustion.

\section{Conclusions}

This research has analyzed the applicability of heat transfer equations to hydrogen combustion. The conclusions are as follows:

(1) The application of the heat transfer equations derived for hydrocarbon combustion engines to hydrogen combustion with significantly different properties is not appropriate.

(2) The actual cooling loss in hydrogen combustion is 4 times higher than the value calculated by Woschni's equation.

(3) Woschni's equation is sometimes used with correction constants, but these constants do not adjust the data to accurately describe the actual cooling loss.

(4) A new heat transfer equation that can be used for the analysis of cooling loss for hydrogen combustion is necessary to improve the thermal efficiency of hydrogen fuelled engines.

(5) It is necessary to take the increase in heat transfer coefficient by in-cylinder gas motion due to combustion into consideration for the application of the heat transfer equations to hydrogen combustion.

\section{Acknowledgments}

The authors wish to express their gratitude to Ms. H. Oka, a student at the Musashi Institute of Technology, for her help in the experiments. This study was supported by the Industrial Technology Research Grant Program from the New 
Energy and Industrial Technology Development Organization (NEDO) of Japan.

\section{References}

[1] Shudo, T., Nakajima, Y., Futakuchi, T., Thermal Efficiency Analysis in a Hydrogen Premixed Combustion Engine, JSAE Review, Vol.21, No.2, (2000).

[2] Shudo, T., Nabetani, S., Nakajima, Y., Analysis of the Degree of Constant Volume and Cooling Loss in a Spark Ignition Engine Fuelled with Hydrogen, International Journal of Engine Research, Vol.2, No.1, (2001).

[3] Shudo, T., Nabetani, S., Analysis of Degree of Constant Volume and Cooling Loss in a Hydrogen Fuelled SI Engine, SAE Paper, No.2001-01-3561, (2001).

[4] Woschni,G., A Universally Applicable Equation for the Instantaneous Heat Transfer Coefficient in the Internal Combustion Engine, SAE Paper, No.670931, (1967).

[5] Eichelberg, G., Some New Investigations on Old Combustion Engine Problems, Engineering, (1939).

[6] Van Tyen, H.W., Methode zur Berechung der Zylinderbuchen-temperaturen in Dieselmotoren, Dissertation Th. Delft, (1962).

[7] Zeman, J., Verdichtungsverluste bei kleineren Zweitakmotoren, Forsch Hert, No.3, (1935).

[8] Nusselt,W., Der Warmeubergang in der Verbrennungs-kraftmaschine, V.D.I. Forschungsheft, No.264, (1923).

[9] Shudo, T., Nabetani, S., Nakajima, Y., Influence of Specific Heats on Indicator Diagram Analysis in a Hydrogen-Fuelled SI Engine, JSAE Review, Vol.22, No.2, (2001).

[10] Shudo, T., Tsuga, K., Analysis of Direct Injection SI Stratified Combustion in Hydrogen Lean Mixture -Combustion Promotion and Cooling Loss by Hydrogen-, International Journal of Automotive Technology, Vol.2, No.3, (2001).

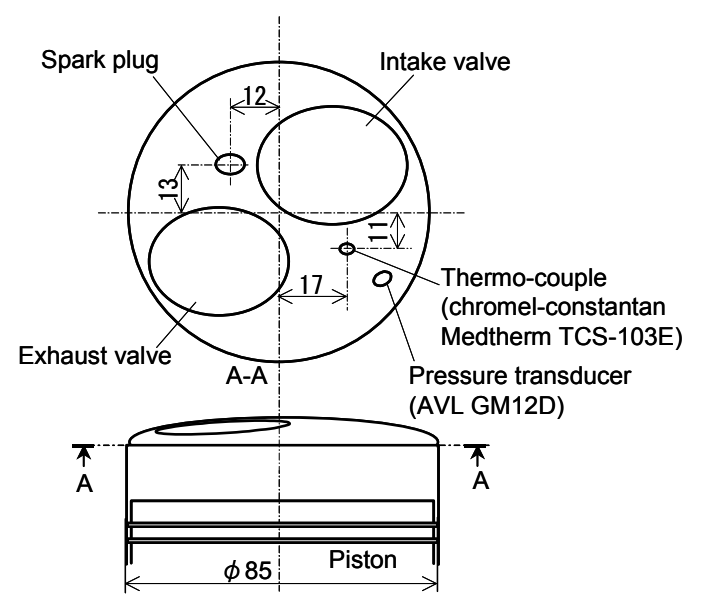

Fig.1 Combustion chamber geometry 


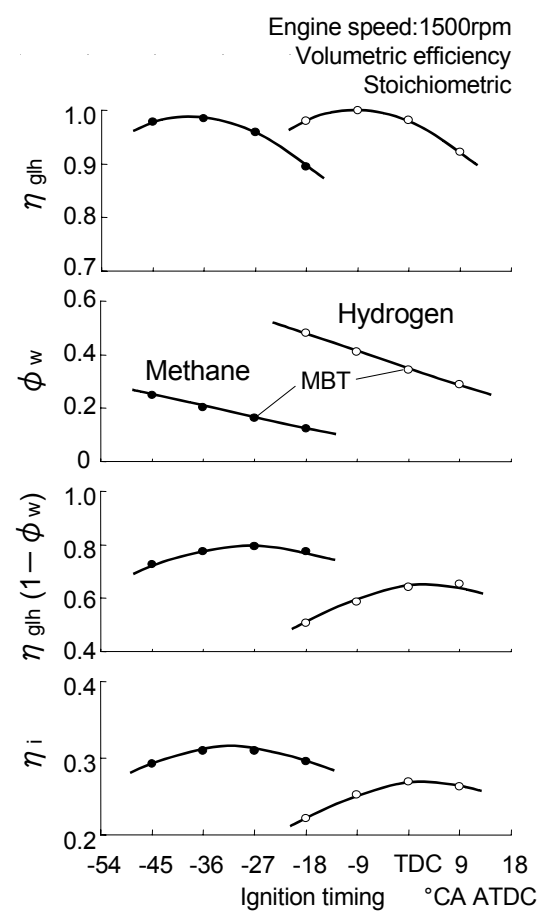

Fig.3 Factors influencing thermal efficiency
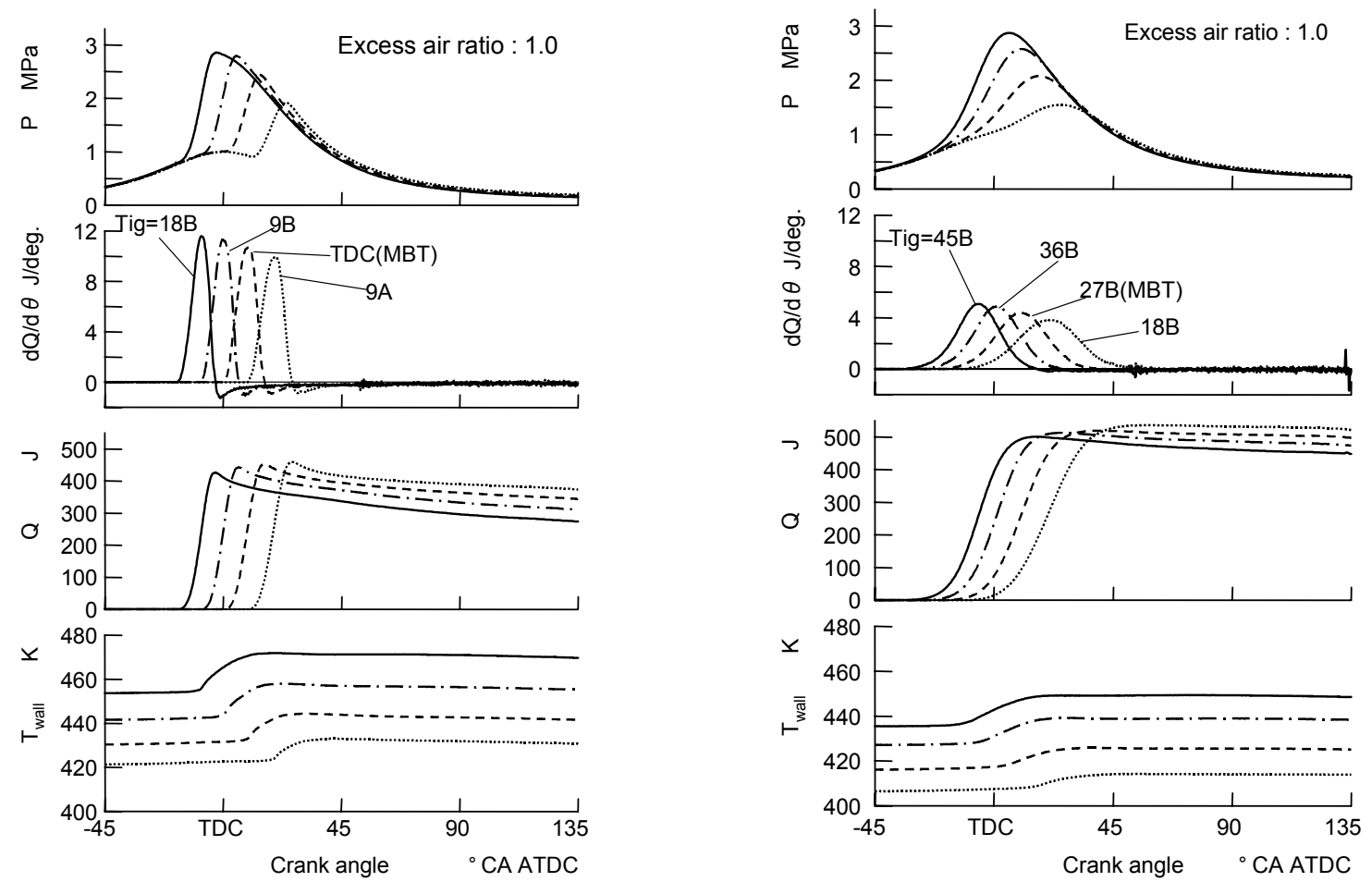

(a) Hydrogen combustion

(b) Methane combustion

Fig. 2 Comparison of hydrogen and methane combustion 

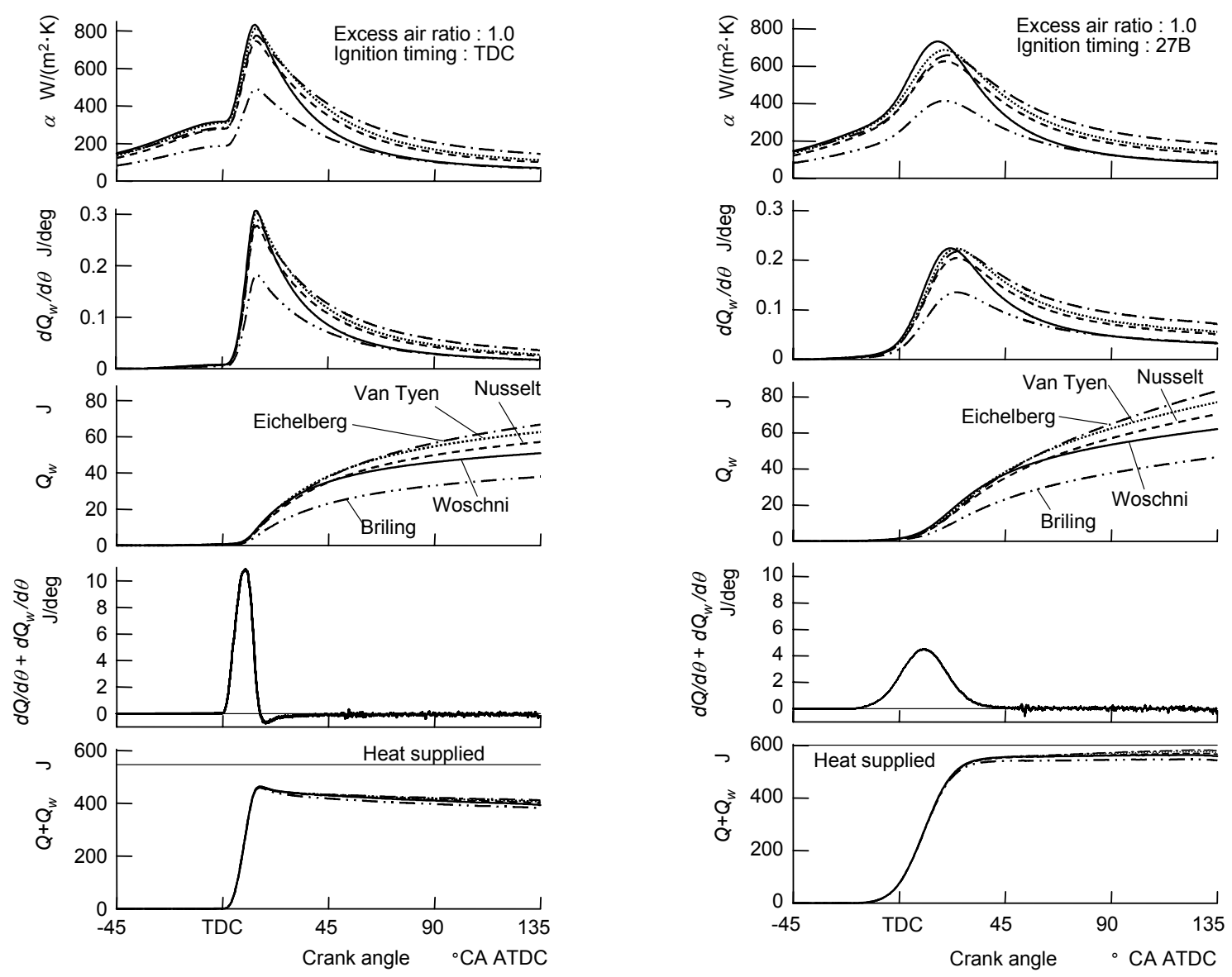

(a) Hydrogen combustion

(b) Methane combustion

Fig.4 Comparison of heat transfer formulas

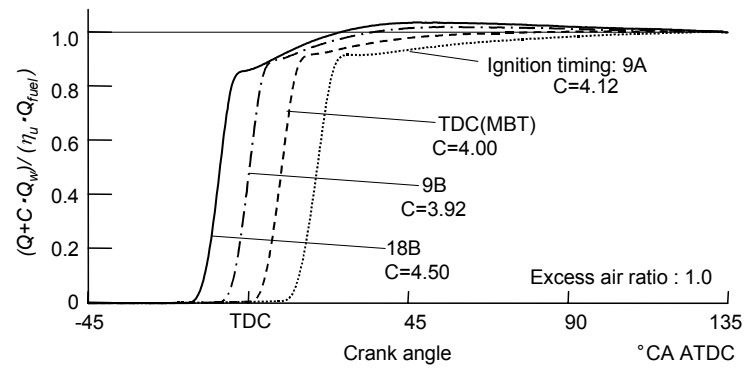

(a) Hydrogen combustion

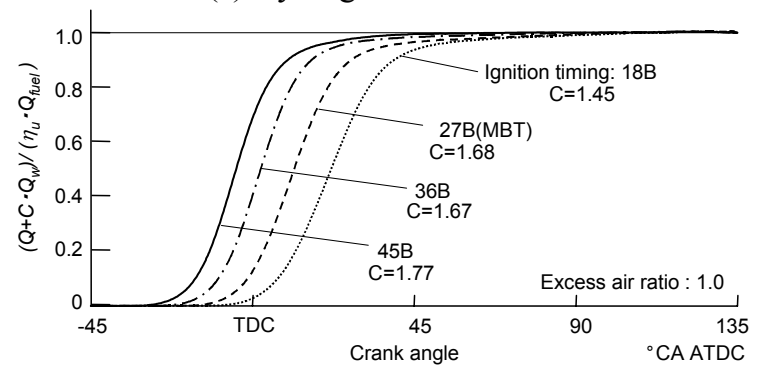

(b) Methane combustion

Fig.5 Normalized cumulative real heat release by Woschni's equation with correction coefficient 


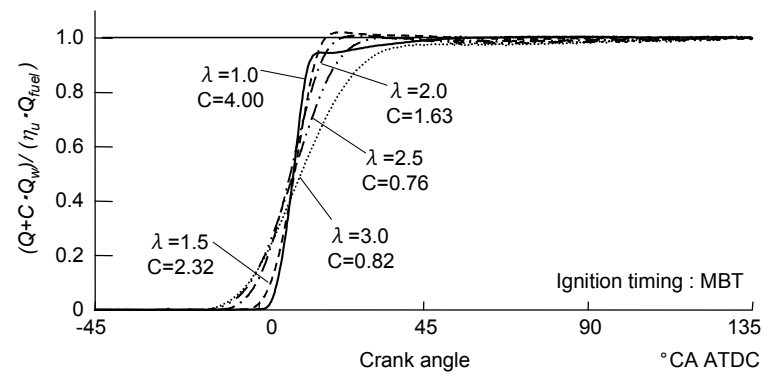

(a) Hydrogen combustion

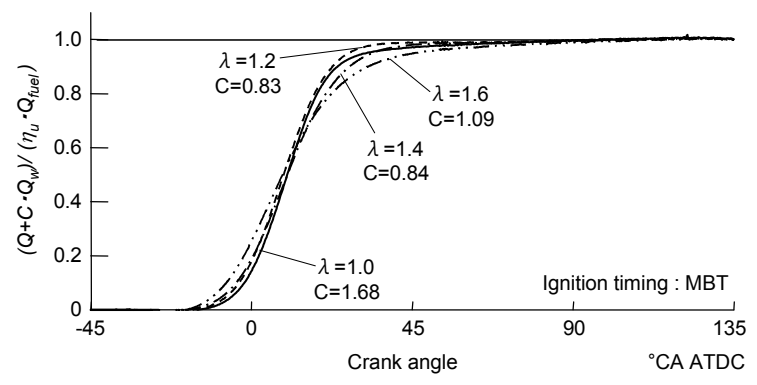

(b) Methane combustion

Fig.6 Normalized cumulative real heat release by Woschni's equation with correction coefficient

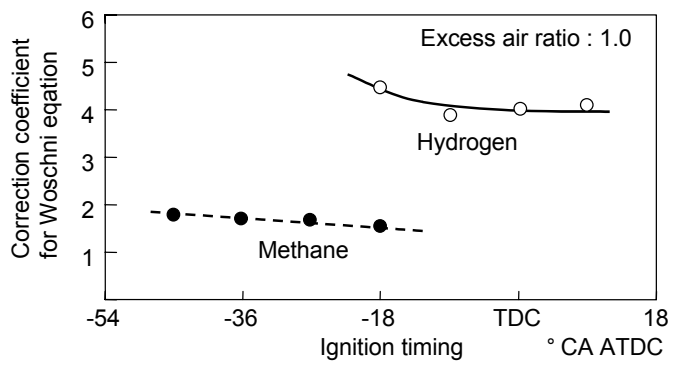

Fig.7 Correction coefficient for different ignition timings

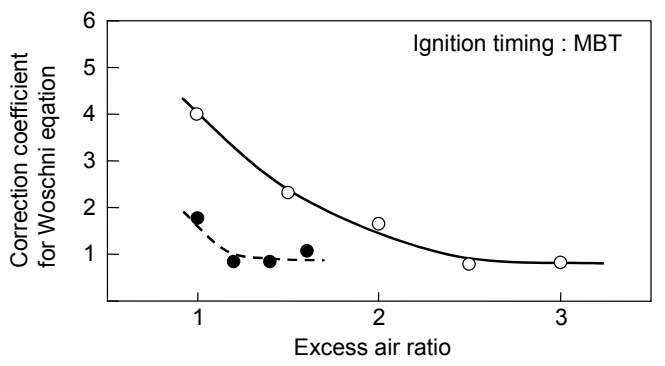

Fig. 8 Correction coefficient for different excess air ratios 